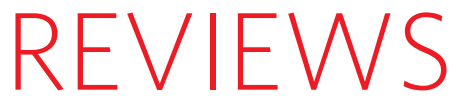

\title{
Temperature sensitivity of soil carbon decomposition and feedbacks to climate change
}

\author{
Eric A. Davidson ${ }^{1} \&$ Ivan A. Janssens ${ }^{2}$
}

Significantly more carbon is stored in the world's soils-including peatlands, wetlands and permafrost-than is present in the atmosphere. Disagreement exists, however, regarding the effects of climate change on global soil carbon stocks. If carbon stored belowground is transferred to the atmosphere by a warming-induced acceleration of its decomposition, a positive feedback to climate change would occur. Conversely, if increases of plant-derived carbon inputs to soils exceed increases in decomposition, the feedback would be negative. Despite much research, a consensus has not yet emerged on the temperature sensitivity of soil carbon decomposition. Unravelling the feedback effect is particularly difficult, because the diverse soil organic compounds exhibit a wide range of kinetic properties, which determine the intrinsic temperature sensitivity of their decomposition. Moreover, several environmental constraints obscure the intrinsic temperature sensitivity of substrate decomposition, causing lower observed 'apparent' temperature sensitivity, and these constraints may, themselves, be sensitive to climate.

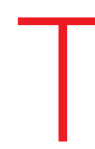

he temperature sensitivity of decomposition of the enormous global stocks of soil organic matter $(\mathrm{SOM})^{1-4}$ has recently received considerable interest, including several high-profile publications supporting opposing views ${ }^{5-14}$. Interest in this topic is high because of its importance in the global carbon $(\mathrm{C})$ cycle and potential feedbacks to climate change ${ }^{15}$. This recent controversy has focused primarily on organic matter in upland mineral soils. These soils have reasonably good drainage and aeration, allowing roots and soil fauna to penetrate into mineral soil layers, thus mixing SOM with mineral particles. Conditions in upland mineral soils are also generally favourable for decomposition, resulting in relatively low carbon densities. In contrast, in wetlands and peatlands where anaerobic conditions frequently persist, decomposition proceeds on top of mineral layers. In soils with permanently frozen layers (permafrost), drainage is also often poor, and organic matter may become buried in deep soil layers through cryoturbation ${ }^{16}$. Thus, wetlands, peatlands and permafrost soils generally contain higher carbon densities than upland mineral soils, and together they make up enormous stocks of carbon globally (Table 1). Moreover, permafrost soils and a large fraction of peatland soils occur at high latitudes, where warming is expected to be greatest, and, indeed, has already begun ${ }^{17,18}$. In this review, we emphasize that decomposition of all types of belowground organic matter should be described by a common set of principles of kinetic theory and environmental constraints. Our objective is to clarify the issues regarding temperature sensitivity of decomposition within a framework that helps to focus the ensuing debate and research.

Factors controlling decomposition of organic matter The stocks of organic matter in soils result from the balance between inputs and outputs of carbon within the belowground environment (Fig. 1). Inputs are primarily from leaf and root detritus. Outputs are much more slowly, and deep layers of organic matter accumulate

dominated by the efflux of carbon dioxide $\left(\mathrm{CO}_{2}\right)$ from the soil surface, although methane $\left(\mathrm{CH}_{4}\right)$ efflux and hydrologic leaching of dissolved and particulate carbon compounds can also be important. The production of $\mathrm{CO}_{2}$ in soils is almost entirely from root respiration and microbial decomposition of organic matter. Like all chemical and biochemical reactions, these processes are temperature-dependent. Root respiration and microbial decomposition are also subject to water limitation. Hence, most empirical models relate the efflux of $\mathrm{CO}_{2}$ from soils (often lumping microbial and root respiration together as 'soil respiration') to temperature and often also to some scalar of soil water content or precipitation ${ }^{19-24}$. This much is not controversial.

The kinetics of enzymatic reactions in well-mixed media are also not controversial. Activation energies are related to the ambient temperature and to the molecular structure of the organic- $\mathrm{C}$ reactant. The

Table 1 | Sizes and vulnerabilities of belowground carbon stocks

\begin{tabular}{lccc}
\hline Carbon 'pool' & $\begin{array}{c}\text { Global } \\
\text { estimates } \\
\text { of size (Pg) }\end{array}$ & $\begin{array}{c}\text { Potential loss by } \\
2100 \text { due to global } \\
\text { warming (Pg) }\end{array}$ & References \\
\hline $\begin{array}{l}\text { Upland soil inventory (3m depth) } \\
\text { Simulated upland soil (litter layer) }\end{array}$ & 2,300 & - & 3,4 \\
Simulated upland soil & 200 & 30 & 38 \\
(mineral layer to 1 m depth) & & & \\
$\quad$ Annually cycling & 20 & 3 & 38 \\
$\begin{array}{l}\text { Decadally cycling } \\
\text { Millennially cycling }\end{array}$ & 700 & 40 & 38 \\
$\begin{array}{l}\text { Peatlands (3 m depth) } \\
\text { Permafrost (3 m depth) }\end{array}$ & $400-500$ & 0 & 38 \\
Although the estimates here are highly uncertain (all estimates are rounded to one \\
significant figure), they help to frame the debate about the relative importance of each \\
type of belowground carbon as a potential feedback to climate change over the next few \\
decades.
\end{tabular}

The Woods Hole Research Center, PO Box 296, Woods Hole, Massachusetts 02543, USA. ²Department of Biology, University of Antwerpen, Universiteitsplein 1, B-2610, Wilrijk, Belgium. 


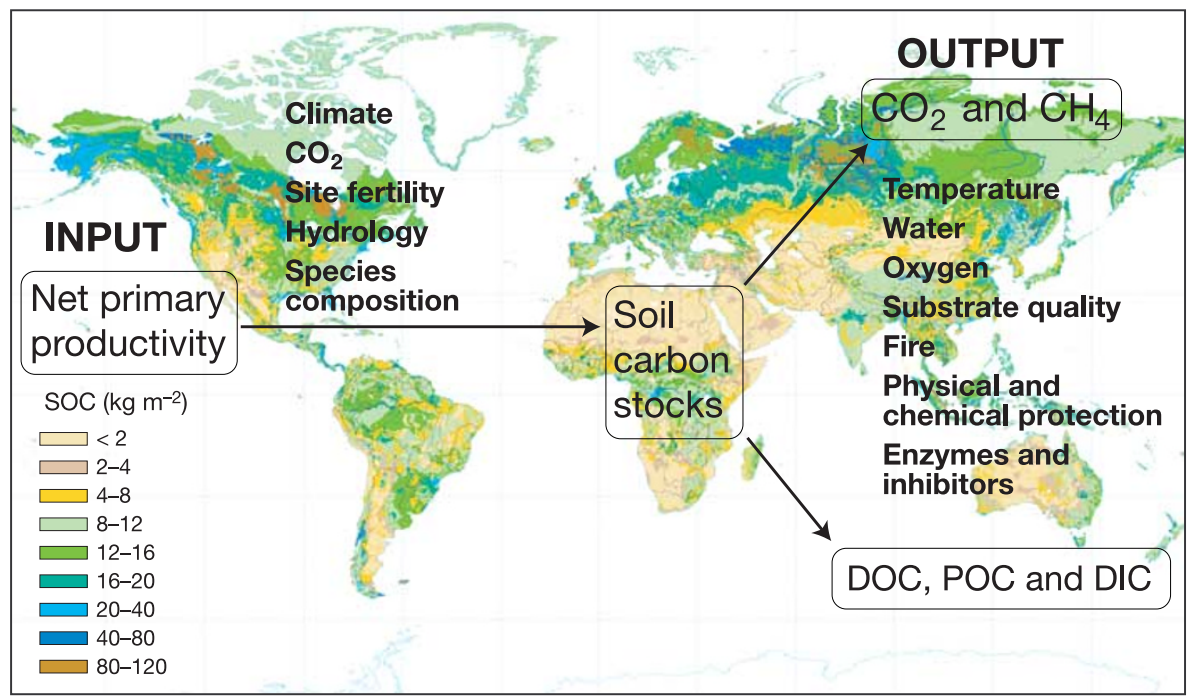

Figure 1 | Diagram of factors controlling the main inputs and outputs of soil carbon, superimposed over a global map of soil organic carbon stocks. While $\mathrm{CO}_{2}$ is the main product of decomposition in soil, $\mathrm{CH}_{4}$, dissolved organic carbon (DOC), particulate organic carbon (POC) in water, and dissolved inorganic carbon (DIC) are also significant exports from some soils. The background soil organic carbon (SOC) map (Miller projection; 1:100,000,000) is from ref. 100.

The $Q_{10}$ for a reaction rate is defined as the factor by which the rate increases with a $10^{\circ}$ rise in temperature. A rule of thumb widely accepted in the biological research community is that the rate of decomposition of SOM, like any other biological reaction rate, tends to double for every $10^{\circ}$ rise in temperature (that is, the $Q_{10}$ of decomposition is two). The origin of this rule-of-thumb, however, and the limits to its validity are less well known. Early experiments by van 't Hoff and colleagues indicated that, around room temperature, reaction rates "roughly double or triple" for every $10^{\circ}$ rise in temperature (that is, reaction rates have $Q_{10}$ values of the order of two to three $)^{84}$. Thus, historically, there has never been any suggestion that the $Q_{10}$ should equal two on the basis of first principles. Moreover, an exponential equation does not always provide the desired relationship between the reaction rate and the temperature. Arrhenius noticed that a $Q_{10}$ as high as two or three cannot originate from the increasing frequency of collisions between the reacting molecules, which only increases by about $1.5 \%$ for every $10^{\circ}$ rise in temperature. Arrhenius also noticed that chemical reactions, even exergonic ones, often require a little 'push' to proceed, which he called the "activation energy" $\left(E_{\mathrm{a}}\right)$. He concluded that the explanation for the unexpected high temperature sensitivity of reaction rates had to be found in the amounts of reactants that possessed sufficient energy to react. Although the actual concentration of a reactant may be relatively constant with temperature, the active fraction that actually takes part in the reaction increases rapidly with temperature. Thus, Arrhenius developed the following equation ${ }^{85}: k=a \exp \left(-E_{a} / R T\right)$ where $k$ is the reaction rate constant; $a$ is a frequency or pre-exponential factor (that is, the theoretical reaction rate constant in the absence of activation energy); $E_{a}$ is the required activation energy; $R$ is the gas constant (8.314 J K${ }^{-1} \mathrm{~mol}^{-1}$ ); and $T$ is the temperature in Kelvin. The term $\exp \left(-E_{\mathrm{a}} / R T\right)$ determines for any given temperature the fraction of the molecules present with energies equal to or in excess of the required activation energy. The Arrhenius function reveals some important properties of the reactions that it describes. For reactants with an $E_{\mathrm{a}}$ around $50 \mathrm{~kJ} \mathrm{~mol}^{-1}$, and at temperatures between $273 \mathrm{~K}$ and $303 \mathrm{~K}$, the $Q_{10}$ of a chemical reaction is around two (Box 1 Figure, upper panel), in agreement with the rule-of-thumb cited above. However, the Arrhenius equation also predicts that the $Q_{10}$ of chemical reactions decreases with increasing temperature (in Box 1 Figure, upper panel), as is also commonly observed in nature ${ }^{86}$. The theoretical explanation for the decrease in $Q_{10}$ with increasing temperature is that as temperature increases, there is a declining relative increase in the fraction of molecules with sufficient energy to react. The Arrhenius function also shows that reactants with higher activation energies (that is, less reactive and more recalcitrant) should have higher temperature sensitivities (Box 1 Figure, upper panel). Hence, theoretical and experimental evidence shows that the $Q_{10}$ of decomposition equals two only under specific conditions.

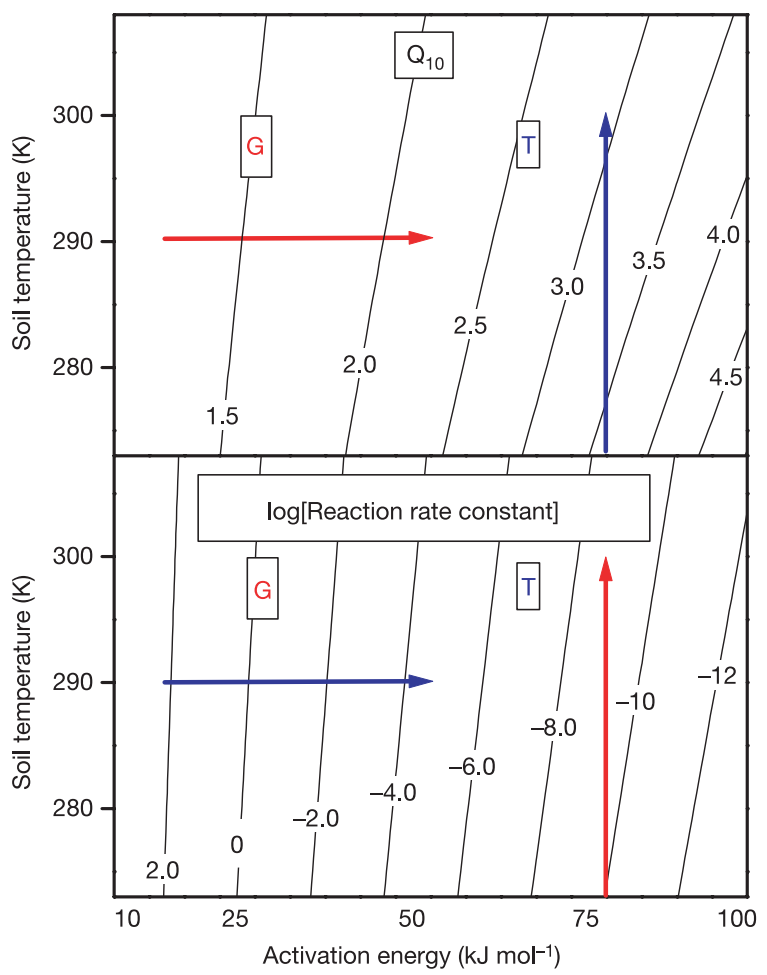

Box 1 Figure | Surface plots of the effects of temperature and activation energy on $Q_{10}$ (upper panel) and reaction rate constant (bottom panel). Reaction rate constants are presented relative to that of glucose at room temperature. For clarity, the logarithm of this value is indicated. The red arrows indicate increasing trends and the blue arrows indicate decreasing trends. That the arrows switch colour between the two panels indicates that both temperature and activation energy have opposite effects on $Q_{10}$ and on the reaction rate. The letters represent glucose $(\mathrm{G})$ and tannin $(\mathrm{T})$ in these graphic presentations of the $Q_{10}$ and reaction rate constant values at room temperature. 
temperature sensitivity of decomposition increases with increasing molecular complexity of the substrate (Boxes 1 and 2). The reaction rates are also modified by substrate concentrations and affinities of the enzymes for the substrates (Box 3).

In applying this knowledge to soil environments the controversy begins (hereafter we use 'soil' loosely to include wetlands, peatlands and permafrost). First, soils contain a 'veritable soup' of thousands of different organic-C compounds, each with its own inherent kinetic properties. Not only do plants produce a wide range of carbon substrates, but plant detritus also undergoes transformations by microbial degradation or by abiotic condensation reactions that produce new aromatic structures, larger molecular weights, insolubility, or other molecular architectures that affect the types and efficacies of enzymes that can degrade them ${ }^{25,26}$. These complex molecular attributes are characterized by low decomposition rates, high activation energies, and inherently high temperature sensitivity (Box 1). We shall call the inherent kinetic properties based on molecular structure and ambient temperature the 'intrinsic temperature sensitivity' of decomposition.

Second, the enzymes for decomposition may be physically or chemically excluded from many of the organic-C substrates within the heterogeneous soil environment ${ }^{26}$, causing substrate limitation at reaction microsites (Box 3). The observed response to temperature under these environmental constraints, which we shall call the 'apparent temperature sensitivity', may be much lower than the intrinsic temperature sensitivity of the substrate (Fig. 2). Conversely, if a temperature-sensitive process alleviates an environmental constraint to decomposition, then the subsequent increase in substrate availability could result in the apparent temperature sensitivity temporarily exceeding the intrinsic temperature sensitivity of the substrate.

The environmental constraints that can temporarily or indefinitely affect apparent temperature sensitivities of decomposition include the following:

\section{Box 2 | Relative versus absolute changes in decomposition rates}

The Arrhenius equation describes changes in relative reaction rates as a function of temperature, but the change in the absolute rate of the reaction is what concerns us most. While the relative rate of decomposition of recalcitrant soil organic matter with high activation energy may be very sensitive to temperature, the change in absolute rate may be small and difficult to detect in experiments. For example, in a temperate ecosystem and under current climate conditions, the annual decomposition of glucose (an easily degradable compound with an $E_{\mathrm{a}}$ of about $30 \mathrm{~kJ} \mathrm{~mol}^{-1}$; ref. 87) would proceed 6.5 million times faster than annual decomposition of a tannin compound with an $E_{\mathrm{a}}$ of about $70 \mathrm{~kJ} \mathrm{~mol}^{-1}$ (assuming equal and unlimited pool sizes; Box 1 Figure, lower panel). If the temperature were to increase by two degrees over the year, glucose decomposition would accelerate by $10 \%$. Because of its higher temperature sensitivity, decomposition of the more recalcitrant tannin would accelerate by $21 \%$. In absolute numbers, this difference in temperature response appears trivial, because glucose would still decompose 5.8 million times faster than the more recalcitrant tannin. Moreover, at similar levels of substrate availability, the warming-induced increase in C losses from glucose will be much larger than those associated with the decomposition of tannin, despite the lower $Q_{10}$ of glucose decomposition. Hence, it is difficult to determine temperature responses of decomposition of recalcitrant organic matter in the presence of more labile compounds, and it is tempting to classify the temperature response of recalcitrant compounds as irrelevant. However, in most environments the stocks of labile and recalcitrant compounds are not equal, with recalcitrant compounds being much more abundant than easily degradable compounds. Thus, even a small change in their decomposition rate could become significant, albeit only at decadal or longer timescales. Hence, sensitivity to temperature changes must be evaluated within the context of pre-existing decomposition rates and substrate availability.
(1) Physical protection. Organic matter may become physically protected in the interior of soil aggregates ${ }^{27,28}$, where microorganisms and their enzymes may have limited access and where oxygen concentrations may also be low. Similarly, organic compounds can be physically protected from degradation by water-soluble enzymes if they have low water solubility or if they occur in hydrophobic domains of humified organic matter ${ }^{29}$.

(2) Chemical protection. Organic matter may become adsorbed onto mineral surfaces through covalent or electrostatical bonds, thus chemically protecting it from decomposition ${ }^{27}$.

(3) Drought. Drought reduces the thickness of soil water films, thus inhibiting diffusion of extracellular enzymes and soluble organic-C substrates and lowering substrate availability at reaction microsites. In fire-prone or drought-prone regions, deposition of volatilized hydrophobic molecules can create water-repellency ${ }^{30}$, which also restricts diffusion of organic matter and enzymes in water films.

(4) Flooding. Flooding slows oxygen diffusion to decomposition reaction sites, often allowing only anaerobic decomposition, which includes fewer and generally slower degradative enzymatic pathways. (5) Freezing. Although enzymatic reactions can occur below $0^{\circ} \mathrm{C}$ (refs 31, 32), the diffusion of substrates and extracellular enzymes within the soil is extremely slow where the extracellular soil water is frozen.

Each of these environmental constraints affects decomposition reaction rates, directly or indirectly, by decreasing substrate concentrations at enzymatic reaction sites. Instead of viewing decomposition

\section{Box $\mathbf{3}$ | The effect of substrate availability on $\mathbf{Q}_{10}$}

The applicability of Arrhenius kinetics may be limited under conditions of changing substrate availability. The importance of substrate availability can easily be demonstrated in models of enzyme-catalysed processes. Enzymes affect reaction rates primarily by decreasing the required activation energy, such that they can occur at ambient temperatures. The importance of substrate availability in enzyme-catalysed reactions is described by Michaelis-Menten kinetics ${ }^{88}$ : the reaction rate is

$V_{\max } \times[S] /\left(K_{m}+[S]\right)$ where $[S]$ is the substrate availability (that is the substrate concentration at the active site of the enzyme), $V_{\max }$ is the maximum reaction rate at a given temperature, and $K_{m}$ is the Michaelis-Menten constant, representing the substrate concentration at which the reaction rate equals $V_{\max } / 2$. When [S] is abundant, $K_{m}$ becomes insignificant, and the temperature response of $V_{\max }$ determines that of the reaction rate. $V_{\max }$ increases with temperature ${ }^{89,90}$ up to an optimum temperature (typically well above ambient conditions), beyond which the enzyme starts to denature and $V_{\max }$ declines rapidly. Therefore, when [S] is abundant and the temperature does not exceed the optimum temperature, $V_{\max }$ follows Arrhenius kinetics and the theory explained in Box 1 is valid. However, when [S] is low, $K_{m}$ becomes relevant. Because the $K_{\mathrm{m}}$ of most enzymes increases with temperature, the temperature sensitivities of $K_{m}$ and $V_{\max }$ can neutralize each other, creating very low apparent $Q_{10}$ values ${ }^{90,91}$. Thus, in addition to substrate quality and temperature, temporal and spatial differences in substrate availability can also contribute to the large variability in $Q_{10}$ observed in nature. This effect of substrate limitation on the temperature sensitivity of decomposition has not yet been incorporated into carbon cycle models. Even when combined, Arrhenius and Michaelis-Menten kinetics may not always describe decomposition reactions. First, these kinetics assume constant enzyme concentrations, which may not be the case when microbial populations fluctuate. Second, temperature can also affect enzyme conformation ${ }^{92}$, isozyme production (isozymes have similar functions but different temperature responses) $)^{93,94}$, and microbial community structure (and thus enzymatic spectrum) ${ }^{54}$. Changes in enzymatic properties, commonly referred to as 'temperature acclimation', could offset temperature-induced increases in respiratory activity. However, although the existence of these processes is beyond doubt, their ecological importance remains to be tested ${ }^{95}$. 
rates only through the lens of the temperature-dependent Arrhenius function of the maximum enzymatic reaction rate $\left(V_{\max }\right.$; Box 1$)$, the substrate concentration and the affinity of the enzyme for the substrate $\left(k_{\mathrm{M}}\right.$, as in Michaelis-Menten kinetics; Box 3) are also crucial for understanding the reaction rate and its sensitivity to temperature. Indeed, conditions of low substrate concentrations at active sites of enzymes may be the rule rather than the exception within the soil matrix.

\section{Common approaches to modelling decomposition}

Most efforts to characterize the kinetics of SOM decomposition have stratified carbon compounds into 'pools' that share similar mean residence times (MRTs) within the soil. The MRT is the inverse of the decomposition reaction rate $(k)$ and therefore reflects a combination of inherent reactivity of the compound and the environmental constraints on its decomposition. The two best-known biogeochemical models of soil carbon dynamics-the CENTURY ${ }^{33}$ and ROTH-C ${ }^{34}$ models-compartmentalize soil carbon into 5-7 conceptual pools, including 2-4 pools of decomposable plant material near the soil surface (litter layer) and three pools of carbon in the mineral soil, with MRTs ranging from years to millennia (Fig. 3). Decomposition of the plant detritus in the litter layers is based on well-supported functions of climate and indices of substrate decomposability, such as carbon-to-nitrogen ratios and lignin content ${ }^{35,36}$. The three $\mathrm{C}$ pools in the mineral soil, from the most labile to the most recalcitrant to decomposition, are called 'fast', 'slow' and 'passive' in CENTURY and 'microbial biomass', 'humified organic matter' and 'inert' in ROTH-C. Many attempts have been made with partial success to measure these various pools through physical and chemical fractionation of the soil ${ }^{13,28}$, but they remain largely simplified modelling constructs. In lieu of discrete pools, a continuum of soil $\mathrm{C}$ substrates of varying chemical complexity and MRTs has also been used to simulate soil $\mathrm{C}$ dynamics ${ }^{37}$.

Although direct measurements of the sizes and MRTs of these

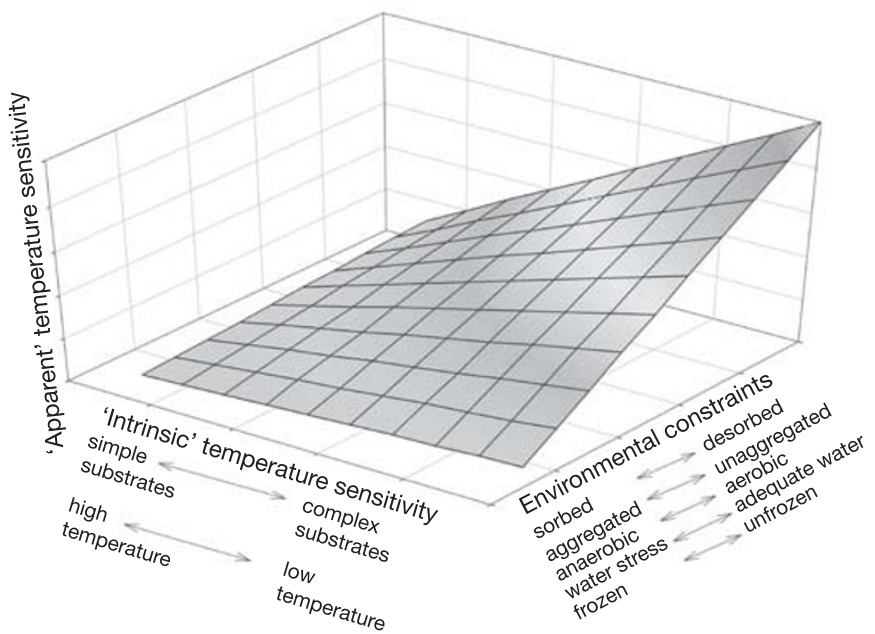

Figure 2 | Factors affecting the 'apparent' sensitivity of decomposition of soil organic matter. The intrinsic temperature sensitivity (as in Arrhenius functions, Box 1) of decomposition of an organic-C substrate is a function of the decomposability of the molecule and the ambient temperature. In general, more complex molecular structures have higher activation energies and, hence, higher temperature sensitivity. However, several environmental constraints on decomposition can dampen or obscure the intrinsic temperature sensitivity by reducing substrate availability, often causing the measured (or 'apparent') temperature sensitivity to be less than expected. The responses to these multiple factors are shown here as a plane for graphic simplicity, but nonlinear functions (for example, oxygen availability) or step functions (for example, melting of permafrost) may be more realistic for some factors. conceptual pools of soil $\mathrm{C}$ remain imperfect, a consensus has emerged that using multi-pool soil $\mathrm{C}$ models to simulate changes in soil $\mathrm{C}$ stocks is a major improvement over treating soil $\mathrm{C}$ as a single, homogeneous pool ${ }^{38-40}$. A substantial fraction of the SOM resides in the most recalcitrant pool that decomposes very slowly. The importance of this model structure was demonstrated when the multipool ROTH-C model was used in lieu of a single soil C pool model for a global simulation of climate change using the Hadley general circulation climate model. Soil $\mathrm{C}$ losses and gains were less severe with the multipool model, both regionally and globally ${ }^{38}$.

While these models have proven effective for explaining local and regional variation in current soil $\mathrm{C}$ stocks and changes in stocks due to management and land-use change, a consensus has not emerged for their applicability to climate change. Typically, most models of soil C dynamics assume that decomposition of all SOM is nearly equally sensitive to temperature ${ }^{12,41,42}$ but this assumption is contrary to kinetic theory (ref. 43; Box 1). Moreover, decomposition rates may be slow (and MRTs may be long) either because the complex structures of the molecules render them resistant to decomposition, or because environmental constraints restrict access of enzymes to the molecules, or because of a combination of these two factors. Both protected simple compounds and more complex unprotected compounds might be lumped together into a common pool with common MRTs. If the causes of varying MRTs and their potential for change are to be understood, the distinction between intrinsic and apparent temperature sensitivities needs to be addressed explicitly.

\section{Evidence for a decomposition feedback to warming}

Discussions of biospheric feedbacks to climatic disruption have been influenced by the perspective that temperature is the dominant limiting factor of respiration, whereas photosynthesis is limited by multiple factors, including light, $\mathrm{CO}_{2}$ concentration, water stress, and nutrient availability ${ }^{44}$. Woodwell ${ }^{45}$ and Jenkinson et al. ${ }^{46}$ argued that respiration of terrestrial ecosystems, including microbial decomposition of SOM, would be more sensitive to global warming than would gross primary productivity. Global warming would thus lead to a net increase of $\mathrm{C}$ release to the atmosphere by the terrestrial biosphere (or less net $\mathrm{C}$ uptake from the atmosphere by the terrestrial biosphere). However, in the absence of a consensus on the temperature sensitivity of decomposition of a large fraction of soil C stocks, the significance of this positive feedback continues to be debated.

Current geographical relationships between climate and SOM stocks provide important clues, such as the presence of large soil C

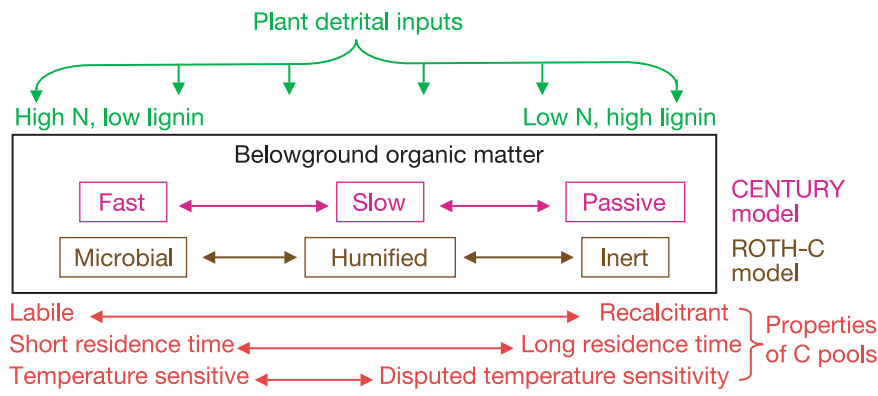

Figure 3 | Diagram of properties of conceptual pools of belowground carbon stocks in two well-known models. The CENTURY ${ }^{33}$ and ROTH-C ${ }^{34}$ models each define three discrete soil carbon pools in the mineral soil that lie roughly along a continuum of decomposability and MRT in the soil. The temperature sensitivity of decomposition of the more recalcitrant forms of $\mathrm{C}$ is the subject of recent debate. Much of this confusion is due to the fact that the recalcitrant pools are mixtures of simple compounds that have long MRTs owing to physical or chemical protection from decomposition and more complex compounds that have inherently low reactivity and require high activation energy for decomposition. 
stocks at high latitudes (Fig. 1). Inferences about the effects of changing climate based on current geographic patterns, however, require the tenuous assumption that a space-for-time substitution adequately describes projections of future scenarios of changing carbon stocks. Nevertheless, in his classical work on soil-forming factors, Jenny ${ }^{47,48}$ described how soil $\mathrm{N}$ concentrations (which covary with soil C) increased with decreasing temperature and increasing precipitation across the Great Plains of central North America. Kirschbaum ${ }^{49}$ pointed out that Jenny's results imply that decomposition does indeed increase more with temperature than does net primary productivity across this gradient, supporting Woodwell's hypothesis ${ }^{45}$. Post et al. ${ }^{50}$ demonstrated similar trends globally, although strong relationships were apparent only for very wet and very dry climates, suggesting that soil water content also plays an important role for constraining rates of decomposition.

Not all gradient studies have supported temperature sensitivity of decomposition ${ }^{11}$, and there are numerous possible explanations. Not withstanding Jenny's example ${ }^{47,48}$ it is possible that growing-season length along some north-south gradients could affect gross primary productivity, and thus $\mathrm{C}$ inputs to soil, as much or more than temperature affects respiration, thus obscuring the effect of temperature on decomposition when interpreting variation in SOM stocks $^{51}$. Environmental constraints to decomposition could also covary with temperature along a particular study transect if factors such as mineralogy, clay content, aggregation, or soil water content also covaried along the same gradient. For example, the presence of clay-sized minerals that effectively adsorb organic matter and retain soil moisture can be related to temperature-dependent processes, such as the effects of previous glaciations that expose new bedrock and biogenic production of acids that promote mineral weathering ${ }^{52}$. Finally, in the example of an observed positive relationship between temperature and soil $\mathrm{C}$ stocks along a climate gradient in Finland ${ }^{11}$, the inferred temperatureinsensitivity of decomposition of a large fraction of SOM could be an artefact of model assumptions about fixed or variable mean residence times of conceptualized soil $\mathrm{C}$ pools ${ }^{53}$. We will return to this issue of the consequences of model assumptions on interpreted temperature sensitivities.

When analysing any geographical trend, it is important to remember that instantaneous temperature responses of decomposition of current $\mathrm{C}$ stocks reflect the relative abundances of organic- $\mathrm{C}$ substrates of differing kinetic properties. Those relative substrate abundances result, in part, from environmental constraints to decomposition during the climate and disturbance history of the soil. For example, the decomposition of organic matter in a highly weathered mature tropical forest soil with high clay content may, on average, have low apparent temperature sensitivity because of chemical protection of a large fraction of soil $\mathrm{C}$ on mineral surfaces. In contrast, the apparent temperature sensitivity may, on average, be higher in a recently tilled temperate prairie soil because of lower proportions of substrates under environmental constraints to decomposition. Giardina and Ryan ${ }^{6}$ ignored this variation in relative abundances of different soil substrates when they calculated MRTs of a single homogeneous soil $\mathrm{C}$ pool for a number of soil samples from different latitudes and under different temperature regimes in laboratory experiments. Not surprisingly, they found no correlation between calculated total soil C MRTs and either laboratory incubation temperature or the mean annual ambient temperature of the field locations. They correctly proposed that substrate quality and other stabilization mechanisms are important factors affecting variation of soil $\mathrm{C}$ stocks among study sites, but they incorrectly concluded that the temperature sensitivity of decomposition is unimportant. Temperature insensitivity implies zero activation energies of decomposition, which is impossible for biochemical processes. The analysis by Giardina and $\operatorname{Ryan}^{6}$ also did not take into account that the abundance of the various carbon substrates (or 'pools'), with differing intrinsic temperature sensitivity and under differing constraints to decomposition, are themselves partly the result of climate effects (Box 4).

In addition to observations of natural gradients, several studies of the temperature sensitivity of decomposition have been carried out in the laboratory and in field experiments. Fang et al. ${ }^{9}$ experimentally applied multiple cycles of varying temperature during a 108-day incubation and estimated the temperature sensitivity for each cycle. The temperature sensitivities of decomposition were not significantly different for the most labile carbon that was respired early in the incubation and for the less labile carbon being respired at the end of the incubation period. They also conducted the experiment on soils from the surface and from deeper soil horizons, the latter presumably having more recalcitrant $\mathrm{C}$ associated with mineral surfaces. Again, no statistically significant differences in temperature sensitivities were observed. While the results of Fang et al. ${ }^{9}$ refuted the notion proposed by others ${ }^{6,11,54,55}$ that decomposition of the more recalcitrant pools would be less sensitive to temperature than the more labile pools, their results are still contrary to kinetic theory, which indicates higher intrinsic temperature sensitivity for decomposition of the recalcitrant $\mathrm{C}$ pools.

In contrast, Knorr et al. ${ }^{10}$ came to a conclusion consistent with kinetic theory when they fitted data from a laboratory soil incubation experiment ${ }^{56}$ to a multi-pool soil C model. They calculated not only that decomposition responded positively to temperature for a highly labile pool, but also that decomposition of a less labile pool exhibited higher temperature sensitivity. Most of the SOM resided in a third recalcitrant pool that did not decompose significantly during the

\section{Box 4 | Assumptions of curve fitting}

In the Arrhenius function shown in Box 1, $E_{\mathrm{a}}$ is clearly a variable that is fitted to observational data to determine a temperature sensitivity of a reaction. A debate has recently emerged, however, whether the pre-exponential factor (a), should be a constant or a variable $57,61,62$. From a purely mathematical perspective, the statistical fits of $E_{a}$ and $a$ are not independent, and so the decision to keep $a$ constant or allow it to vary affects the fitted value of $E_{a}$ (ref. 62). Because the $a$-term is defined as the theoretical reaction rate constant in the absence of activation energy, it makes sense that it might have different values for different substrates ${ }^{53}$. Hence, model fits in which all variation in decomposition rates and temperature sensitivity is attributed to $E_{\mathrm{a}}$ are likely to overemphasize the differences in $E_{\mathrm{a}}$ among compounds. Nonetheless, there is overwhelming evidence that $E_{\mathrm{a}}$ does vary considerably among compounds, and that decomposition of recalcitrant SOM has higher intrinsic temperature sensitivity than decomposition of labile SOM (Box 1). Because the statistical fits of $E_{\mathrm{a}}$ and $a$ are not independent, however, curve fitting is unlikely to have sufficient power to resolve exactly to what degree decomposition of recalcitrant compounds should have higher intrinsic temperature sensitivities. A conceptually separate, but mathematically similar, issue arises when applying the rate constant (k) from the Arrhenius function to simulate decomposition of various soil C pools, using the form: $g(t)=\sum c_{i} e^{-k_{i} t}$, where $g(t)$ is the remaining carbon fitted to observational data and $c_{i}$ are the initial sizes of carbon 'pools' of varying degrees of decomposability. Note the mathematical similarity between this function and the Arrhenius function (Box 1), from which the $k_{i}$ value for each $c_{i}$ in this equation is derived. Just as the variability of the $a$-term in the Arrhenius function is being debated, a debate has also emerged in the literature as to whether temperature dependence should reside only in the $k_{i}$-terms or also in the $c_{i}$-terms ${ }^{96-99}$. While the $k_{i}$-term describes the current instantaneous decomposition rate and its temperature sensitivity, the relative sizes of the carbon pools $\left(c_{i}\right)$ of varying degrees of decomposability were determined over longer timescales and may also partially be a consequence of climatic history, including temperature. In many statistical fits of observational data, these two terms $\left(k_{i}\right.$ and $\left.c_{i}\right)$ are correlated ${ }^{98}$, and so it is impossible to determine where the temperature sensitivity lies by statistical curve fitting alone. 
incubation period. If not partitioned out in the model, this large pool of recalcitrant organic matter would obscure the temperature sensitivity of the two smaller, more labile pools. Experimental support for kinetic theory was also obtained from incubation experiments of leaf and root litter with varying substrate quality ${ }^{14}$.

However, each of these studies ${ }^{9-11,14}$ relied upon curve fitting to demonstrate temperature sensitivities to decomposition, and doubts may arise from the underlying assumptions of the models and the power of the statistical tests to detect significantly different curvefitting parameters. It is possible, for example, that Fang et al. ${ }^{9}$ did not find significantly higher temperature sensitivity of the more recalcitrant $C$ pools because of a type II error-accepting a null hypothesis of no statistically significant differences among fitted $E_{\mathrm{a}}$ terms. On the other hand, the Knorr et al. ${ }^{10}$ study has been criticized for creating an artefact of different temperature sensitivities ( $E_{\mathrm{a}}$ terms) between pools because of a model assumption of fixed $a$-terms in the Arrhenius function (ref. 57; Boxes 1 and 4). Furthermore, environmental constraints to decomposition of some of the substrates may have been present during these incubations.

Soil warming experiments in the field have also provided equivocal evidence regarding the temperature sensitivity of decomposition. In these experiments, an initial increase in soil $\mathrm{CO}_{2}$ efflux in response to experimental warming has been observed, but this measurable pulse in decomposition often disappears within a few years ${ }^{54,55,58,59}$. This result, however, must be interpreted with caution because high spatial and temporal variability of measured $\mathrm{CO}_{2}$ efflux rates often preclude powerful statistical tests of small treatment effects, resulting in possible type II errors. Nonetheless, one interpretation of these ephemeral responses has been that only decomposition of the most labile soil $\mathrm{C}$ pool was sensitive to the warming treatment, and that decomposition of the older, more recalcitrant soil $\mathrm{C}$ was not temperature sensitive. Another interpretation has been that roots and soil microbial communities 'acclimate' to the higher-temperature conditions by gradually adapting their metabolism, so that the newly acclimated communities return to respiration rates similar to the pre-treatment levels within a relatively short time (Box 3). However, recent modelling studies ${ }^{10,59,60}$ have demonstrated that these field experimental data are also consistent with a model of a small, labile pool that is quickly exhausted and a larger less-labile pool that is also temperature sensitive, but that decomposes much more slowly. Model fits of these studies appear better with the multipool models, and neither temperature insensitivity nor acclimation needs to be invoked to explain the observations.

Unfortunately, curve fitting of data from laboratory incubations ${ }^{6,9-11,14}$ and soil warming experiments in the field $d^{54,55,58-60}$ is unlikely to resolve the debate about the underlying mechanisms of temperature sensitivities. In a series of discussions of the Knorr et al. ${ }^{10}$ and Fang et al. ${ }^{9}$ papers, the same data fit equally well models with different assumptions and, hence, different interpretations of the temperature sensitivity of decomposition of recalcitrant SOM (refs 57, 61, 62; Box 4). Another limitation to curve fitting is that it focuses on the relationship between measured apparent temperature sensitivity and estimated MRTs of experimentally defined soil C pools, rather than attempting to distinguish between intrinsic and apparent temperature sensitivity of the substrates of decomposition.

Despite these controversies, the observational data are converging to demonstrate that more than one 'pool' along the labile/recalcitrant continuum (Fig. 3) decomposes with detectable apparent temperature sensitivity. Neither the observational data nor the soil $\mathrm{C}$ model simulations, however, have been able to demonstrate a consistent apparent temperature sensitivity of decomposition along the entire spectrum of recalcitrant pools of SOM.

It is tempting to assume that the temperature sensitivity of decomposition of the more recalcitrant forms of SOM is trivial with respect to current concern about feedbacks to global warming, because decomposition of these substrates, even if it is accelerated, contributes so little to instantaneous $\mathrm{CO}_{2}$ fluxes. Nonetheless, because of their large contribution to the soil C stocks, even small changes in the decomposition rates of recalcitrant pools may result in an important change in soil C stocks over decades (Box 2). In fact, we do not know where along the soil- $\mathrm{C}$ continuum or among the discrete conceptual pools of SOM (Fig. 3) apparent temperature sensitivity may become irrelevant to contemporary issues of carbon cycling. More importantly, might the existing environmental constraints to decomposition change with changing climate, thus exposing to decomposition SOM with high intrinsic temperature sensitivity? In our opinion, answering this question would be more informative about biospheric feedbacks to warming than refining the correlation between current apparent temperature sensitivity and MRTs of soil C pools.

\section{Temperature dependence of environmental constraints}

According to kinetic theory, the constraints to decomposition that are caused by biological and chemical processes must themselves be affected by temperature ${ }^{8}$ and perhaps other climatic drivers. Let us now reexamine the five environmental constraints to decomposition listed above in light of the question of their own dependence on climate.

(1) Both climate and management affect aggregate formation (through growth of fungal hyphae and activity of soil fauna), which physically protects SOM. The breakdown of aggregates can also be enzymatic ${ }^{26}$, as the biogenic 'glue' that holds the aggregates together is decomposed. In addition, however, purely physical processes, such as ploughing and the impact of raindrops, also destroy aggregates ${ }^{26}$. These processes are not directly temperature dependent, but are often influenced by climate.

(2) Temperature affects the chemical processes of SOM adsorption and desorption onto mineral surfaces, but little is known about the activation energies of these processes.

(3) The climate-driven hydrologic balance among drainage, precipitation, and evapotranspiration determines soil water film thickness through which the diffusion of soluble organic-C substrates and extracellular enzymes occurs. Likewise leaf litter hydrophobicity associated with drought-prone and fire-prone ecosystems is also affected by climate.

(4) Climate-driven flooding of wetlands and peatlands determines oxygen supply for decomposition. Both precipitation and evapotranspiration are likely to change in many regions of the world owing to climatic disruption ${ }^{63}$, tipping the hydrologic balance towards summertime drying of many mid-continental peatlands and wetlands and thus exposing large stocks of carbon substrates to aerobic decomposition.

(5) Melting of permafrost will expose organic matter with wideranging kinetic properties that are not currently expressed in frozen soil. Once the soil thaws, a major constraint to decomposition will be removed.

Most of the current debate regarding the temperature sensitivity of decomposition of organic matter in mineral soils concerns only physical and chemical protection within the mineral soil matrix. While these processes are extremely important contributors to variability of soil carbon stocks and soil fertility, the extent to which they will participate in positive or negative feedbacks to climate change is not clear. Adsorption and desorption processes are both temperature sensitive and might both increase such that the net effect would be minimal over the next few decades. In contrast, the last two constraints to decomposition-frozen soils and oxygen limitation due to flooding-are likely to be subject to rapid changes under plausible climate change scenarios.

When decomposition in wetlands and peatlands slows owing to lack of oxygen during periods of flooding, the low oxygen concentrations inhibit the activity of phenol oxidase, causing accumulation of phenolic compounds ${ }^{64}$. These phenolic compounds inhibit the activity of hydrolase enzymes responsible for decomposition, thus slowing decomposition further. This inhibition is quickly reversible 
once peat becomes aerobic. Hence, the 400-500 Pg $\left(1 \mathrm{Pg}=10^{15} \mathrm{~g}\right)$ carbon in wetlands and peatlands ${ }^{4,65}$, which has been accumulating over centuries and millennia, is 'stable' only as long as anaerobic conditions are sustained. In the continental areas where summertime soil moisture is expected to decrease ${ }^{63}$, the upper layers of peat could dry out. An estimated 100 Pg carbon could become aerobic and thus available for decomposition (Table 1; ref. 4). Evidence that this process may already be occurring comes from recently repeated inventories of soils of England and Wales, which show that peat soils and bogs lost carbon at a faster rate than upland soils over the last 25 years (ref. 5 ).

Carbon losses from peatlands will not necessarily enhance global warming if an increased emission of $\mathrm{CO}_{2}$ is compensated by a decrease in the current net emissions of $\mathrm{CH}_{4}$ (ref. 66). The greenhouse warming potential of $\mathrm{CH}_{4}$ on a per molecule basis is 23 times higher than $\mathrm{CO}_{2}$ on a 100 -year timescale ${ }^{67}$. Likewise, growth of forest vegetation on previously flooded land could sequester significant amounts of $\mathrm{C}$ in $\operatorname{wood}^{68}$, although the net carbon balance remains uncertain ${ }^{69}$. On the other hand, carbon in desiccated peat is also subject to natural and human fires, rapidly releasing huge amounts of carbon to the atmosphere. Siberian and Canadian peatlands are already subject to important peat losses during fire-prone dry years ${ }^{70}$ and the combination of higher temperatures and peat drying may increase fire frequency and severity ${ }^{71}$. During the 1997 El Niño, $0.6-0.8 \mathrm{Pg}$ of $\mathrm{C}$ ( $10 \%$ of anthropogenic emissions) was lost owing to peat fires in Indonesia alone ${ }^{72}$. Peat fires could thus have larger effects on the soil carbon feedback than any of the biotic responses presented above $^{73}$.

Permafrost soils store a similar amount of organic matter as peatlands (Table 1). In these soils with permanently frozen layers, plant litter accumulates both at the surface and on top of the permafrost table through a mixing process called cryoturbation ${ }^{16}$. When permafrost thaws, large amounts of otherwise mostly unprotected carbon become available for decomposition ${ }^{74,75}$. A gradual net loss of deep soil $\mathrm{C}$ in a boreal forest has also been attributed to warming-induced deepening of the layer of seasonal biological activity $^{76}$. One estimate suggests that global warming could thaw $25 \%$ of the permafrost area by 2100 (ref. 77), thus rendering about $100 \mathrm{Pg}$ carbon vulnerable to decay (Table 1 ; ref. 4).

Permafrost thaw creates a mosaic of flooded areas interspersed within higher dry areas. In the drier thawed areas, much of the large substrate pool is likely to decompose relatively quickly. Within the flooded thawed areas (thermokarst lakes), however, anaerobic decomposition of organic matter is likely to proceed more slowly, but produces large $\mathrm{CH}_{4}$ emissions ${ }^{78}$, which could constitute a stronger feedback to the climate system than the larger soil $\mathrm{C}$ losses from the drier areas. To further complicate matters, recent evidence indicates that thermokarst lakes are increasing in abundance in the most northern range of permafrost, owing to an initial increase in thermokarst development in response to warming, whereas thermokarst lakes are draining and disappearing in the southern range of permafrost, owing to more advanced degradation of permafrost ${ }^{79}$.

Frozen and anaerobic conditions merely suspend organic matter in decomposition time, rather than transform it into inherently recalcitrant material. The term 'stabilization' has not been rigorously defined with respect to soil carbon dynamics, and it would be misleading to refer to organic $\mathrm{C}$ in wetlands and permafrost as 'stabilized' in the same sense that organic $\mathrm{C}$ is stabilized in mineral soils when it is adsorbed to mineral surfaces or protected in aggregate interiors. In both cases, intrinsic kinetic properties of decomposition of the organic-C substrates are suppressed by environmental constraints (Fig. 2), but the anaerobic and frozen conditions of wetland, peatland, and permafrost soils are more likely to be subject to rapid change. Unlike the debate over mineral soils, the unresolved question regarding peatlands and permafrost is not the degree to which the currently constrained decomposition rates are temperature sensitive, but rather how much permafrost is likely to melt and how much of the peatland area is likely to dry significantly. Such regional changes in temperature, precipitation, and drainage are still difficult to predict in global circulation models. Hence, the climate change predictions, as much as our understanding of carbon dynamics, limit our ability to predict the magnitude of likely vulnerability of peat and permafrost carbon to climate change. Assuming that $25 \%$ of the estimated stocks of carbon in peatlands and permafrost is subject to loss due to global warming in the twenty-first century, this potential loss would be two to three times larger than simulated $\mathrm{C}$ losses from mineral soils using current soil C models (Table 1; refs 38, 42).

Other global change processes, such as $\mathrm{CO}_{2}$ fertilization, $\mathrm{N}$ deposition, improved soil management (for example, conservation tillage), and land-use change could also change soil carbon stocks. We have not addressed these changes, partly because our charge in this review is to focus on the temperature sensitivity controversy, but also because compelling evidence is lacking for globally significant soil C sinks by these processes ${ }^{15,80-83}$. In contrast, those belowground carbon pools where environmental constraints to decomposition are themselves highly sensitive to climate may become increasingly important positive feedbacks as global climatic disruption becomes more pronounced.

\section{Conclusions and future research directions}

A significant fraction of relatively labile SOM is clearly subject to temperature-sensitive decomposition, but another significant fraction of SOM remains under environmental constraints that often obscure the intrinsic temperature sensitivity of its decomposition. The interpretations of natural climatic gradients and of laboratory and field experiments designed to quantify various carbon fractions and degrees of temperature sensitivity are highly dependent upon model assumptions and curve fitting techniques. Such studies have yielded valuable insight into soil carbon dynamics, but they have not resolved the overall response of global soil C stocks or the magnitude of expected feedbacks to climatic disruption. Moreover, dividing SOM into only temperature-sensitive and apparently temperatureinsensitive pools is far too simplistic.

Extrapolation of decomposition rates into a future warmer world based on observations of current apparent temperature sensitivities is inadequate. Rather, we need to understand how substrate availability will change and how a changing set of environmental constraints to decomposition in a future climate will determine the future apparent temperature sensitivity of decomposition. Perhaps a new way forward would be a further reductionist effort to distinguish between inherent kinetic properties of individual substrates and the suite of environmental constraints to decomposition that frequently exist in situ. Our ability to identify and characterize soil substrates is growing with new developments in nuclear magnetic resonance and other technologies, but the task is enormous given the diversity of soil C substrates common in soils. Even when structures are identified within the soil, their concentrations at reactive sites of enzymes are more difficult to estimate. Nevertheless, merging the concepts of substrate availability, such as Michaelis-Menten kinetics, with the temperature sensitivity prescribed by Arrhenius kinetics may provoke new measurement and modelling approaches for soil $\mathrm{C}$ dynamics. The multiple processes of environmental constraints that govern availability of substrates to enzymes should be explicitly described and studied within the context of climate change.

Regardless of the experimental and modelling approaches used, the debate about the temperature sensitivity of decomposition should be broadened beyond upland mineral soils specifically to include wetlands, peatlands and permafrost soils. These are the most obvious environments in which current constraints on decomposition are likely to change as a result of climatic disruption, thus potentially exposing large stocks of $\mathrm{C}$ to less constrained decomposition during the next few decades. A high research priority should be 
how the constraints to decomposition in these environments are sensitive to climate.

1. Batjes, N. H. Total carbon and nitrogen in the soils of the world. Eur. J. Soil Sci. 47, 151-163 (1996)

2. Eswaran, H., Van Den Berg, E. \& Reich, P. Organic carbon in soils of the world. Soil Sci. Soc. Am. J. 57, 192-194 (1993).

3. Jobbágy, E. G. \& Jackson, R. B. The vertical distribution of soil organic carbon and its relation to climate and vegetation. Ecol. Appl. 10, 423-436 (2000).

4. Gruber, N. et al. in Toward $\mathrm{CO}_{2}$ Stabilization: Issues, Strategies, and Consequences (eds Field, C. B. \& Raupach, M. R.) 45-76 (Island Press, Washington, DC, 2004).

5. Bellamy, P. H., Loveland, P. J., Bradley, R. I., Murray Lark, R. \& Kirk, G. Carbon losses from all soils across England and Wales 1978-2003. Nature 437, 245-248 (2005)

6. Giardina, C. P. \& Ryan, M. G. Evidence that decomposition rates of organic matter in mineral soil do not vary with temperature. Nature 404, 858-861 (2000).

7. Davidson, E. A., Trumbore, S. E. \& Amundson, R. Soil warming and organic carbon content. Nature 408, 789-790 (2000).

8. Thornley, J. H. M. \& Cannell, M. G. R. Soil carbon storage response to temperature: an hypothesis. Ann. Bot. (Lond.) 87, 591-598 (2001).

9. Fang, C., Smith, P., Moncrieff, J. B. \& Smith, J. U. Similar response of labile and resistant soil organic matter pools to changes in temperature. Nature 433 57-59 (2005)

10. Knorr, W., Prentice, I. C., House, J. I. \& Holland, E. A. Long-term sensitivity of soil carbon turnover to warming. Nature 433, 298-301 (2005)

11. Liski, J., Ilvesniemi, H., Mäkelä, A. \& Westman, C. J. CO $\mathrm{CO}_{2}$ emissions from soil in response to climatic warming are overestimated- the decomposition of old soil organic matter is tolerant of temperature. Ambio 28, 171-174 (1999).

12. Kirschbaum, M. U. F. The temperature dependence of soil organic matter decomposition, and the effect of global warming on soil organic $C$ storage. Soil Biol. Biochem. 27, 753-760 (1995).

13. Trumbore, S. E., Chadwick, O. A. \& Amundson, R. Rapid exchange between soil carbon and atmospheric carbon dioxide driven by temperature change. Science 272, 393-396 (1996)

14. Fierer, N., Craine, J. M., McLaughlan, K. \& Schimel, J. P. Litter quality and the temperature sensitivity of decomposition. Ecology 86, 320-326 (2005).

15. Schlesinger, W. H. \& Andrews, J. A. Soil respiration and the global carbon cycle. Biogeochemistry 48, 7-20 (2000).

16. Bockheim, J. G. \& Tarnocai, C. Recognition of cryoturbation for classifying permafrost-affected soils. Geoderma 81, 281-293 (1998).

17. Arctic Climate Impact Assessment (ACIA). Impacts of a Warming Arctic: Arctic Climate Impact Assessment (Cambridge Univ. Press, Cambridge, 2004); $\langle$ http://amap.no/acia/〉.

18. Chapin, F. S. III et al. Role of land-surface changes in Arctic summer warming. Science 310, 657-660 (2005).

19. Davidson, E. A., Verchot, L. V., Cattânio, J. H., Ackerman, I. L. \& Carvalho, J. E. M. Effects of soil water content on soil respiration in forests and cattle pastures of eastern Amazonia. Biogeochemistry 48, 53-69 (2000).

20. Hanson, P. J. et al. in North American Temperate Deciduous Forest Responses to Changing Precipitation Regimes (eds Hanson, P. J. \& Wullschleger, S. D.) 163-189 (Springer, New York, 2003).

21. Janssens, I. A. et al. in Canopy Fluxes of Energy, Water and Carbon Dioxide of European Forests (ed. Valentini, R.) 235-256 (Springer, Berlin, 2003).

22. Raich, J. W. \& Potter, C. S. Global patterns of carbon dioxide emissions from soils. Glob. Biogeochem. Cycles 9, 23-36 (1995)

23. Reichstein, M. et al. Modeling temporal and large-scale spatial variability of soil respiration from soil water availability, temperature and vegetation productivity indices. Glob. Biogeochem. Cycles 17, 15.1-15.15 (2003).

24. Schlentner, R. E. \& Van Cleve, K. Relationships between $\mathrm{CO}_{2}$ evolution from soil, substrate temperature, and substrate moisture in four mature forest types in interior Alaska. Can. J. For. Res. 15, 97-106 (1985).

25. Kelley, K. R. \& Stevenson, F. J. in Humic Substances in Terrestrial Ecosystems (ed. Picolo, A.) 407-427 (Elsevier, Amsterdam, 1996).

26. Sollins, P., Homann, P. \& Caldwell, B. A. Stabilization and destabilization of soi organic matter: mechanisms and controls. Geoderma 74, 65-105 (1996).

27. Oades, J. M. The retention of organic matter in soils. Biogeochemistry 5, 35-70 (1988)

28. Six, J. et al. Measuring and understanding carbon storage in afforested soils by physical fractionation. Soil Sci. Soc. Am. J. 66, 1981-1987 (2002).

29. Spacini, R. et al. Increased soil organic carbon sequestration though hydrophobic protection by humic substances. Soil Biol. Biochem. 34, 1839-1851 (2002).

30. McHale, G. et al. Water-repellent soil and its relationship to granularity, surface roughness and hydrophobicity: a materials science view. Eur. J. Soil Sci. 56, 445-452 (2005)

31. Mikan, C. J. et al. Temperature controls of microbial respiration in arctic tundra soils above and below freezing. Soil Biol. Biochem. 34, 1785-1795 (2002).

32. Elberling, B. \& Brandt, K. K. Uncoupling of microbial $\mathrm{CO}_{2}$ production and release in frozen soil and its implications for field studies of arctic $\mathrm{C}$ cycling. Soil Biol. Biochem. 35, 263-272 (2003).

33. Parton, W. J., Schimel, D. S., Cole, C. V. \& Ojima, D. S. Analysis of factors controlling soil organic matter levels in Great Plains Grasslands. Soil Sci. Soc. Am. J. 51, 1173-1179 (1987).

34. Jenkinson, D. S. The turnover of organic carbon and nitrogen in soil. Phil. Trans. R. Soc. B 329, 361-368 (1990)

35. Meentemeyer, $\mathrm{V}$. Macroclimate and lignin control of litter decomposition rates. Ecology 59, 465-472 (1978).

36. Melillo, J. M. et al. Nitrogen and lignin control of hardwood leaf litter decomposition dynamics. Ecology 63, 621-626 (1982).

37. Ågren, G. I. \& Bosatta, E. Theoretical Ecosystem Ecology-Understanding Element Cycles (Cambridge Univ. Press, Cambridge, 1998).

38. Jones, C. et al. Global climate change and soil carbon stocks; predictions from two contrasting models for the turnover of organic carbon in soil. Glob. Change Biol. 11, 154-166 (2005)

39. Powlson, D. Will soil amplify climate change? Nature 433, 204-205 (2005).

40. Trumbore, S. Age of soil organic matter and soil respiration: radiocarbon constraints on belowground C dynamics. Ecol. Appl. 10, 399-411 (2000)

41. Jenkinson, D. S. \& Rayner, J. H. The turnover of soil organic matter in some of the Rothamsted Classical Experiments. Soil Sci. 123, 298-305 (1977).

42. Schimel, D. S. et al. Climatic, edaphic, and biotic controls over storage and turnover of carbon in soils. Glob. Biogeochem. Cycles 8, 279-293 (1994).

43. Bosatta, E. \& Ågren, G. I. Soil organic matter quality interpreted thermodynamically. Soil Biol. Biochem. 31, 1889-1891 (1999).

44. Farquhar, G. D., von Caemmerer, S. \& Berry, J. A. A biochemical model of photosynthetic $\mathrm{CO}_{2}$ fixation in leaves of $\mathrm{C}_{3}$ species. Planta 149, 78-90 (1980).

45. Woodwell, G. M. in Changing Climate 216-241 (NAS Press, Washington DC, 1983).

46. Jenkinson, D. S. et al. model estimates of $\mathrm{CO}_{2}$ emissions from soil in response to global warming. Nature 351, 304-306 (1991).

47. Jenny, H. Factors of Soil Formation. A System of Quantitative Pedology 1st edn (McGraw-Hill Book Co, New York, 1941).

48. Jenny, H. The Soil Resource, Origin and Behavior (Springer, New York, 1980).

49. Kirschbaum, M. U. F. Will changes in soil organic carbon act as a positive or negative feedback on global warming. Biogeochemistry 48, 21-51 (2000).

50. Post, W. M., Emanuel, W. R., Zinke, P. J. \& Stangenberger, A. G. Soil carbon pools and world life zones. Nature 298, 156-159 (1982)

51. Janssens, I. A. et al. Productivity overshadows temperature in determining soi and ecosystem respiration across European forests. Glob. Change Biol. 7, 269-278 (2001).

52. Chadwick, O. A. et al. Carbon dioxide consumption during soil development. Biogeochemistry 24, 115-127 (1994).

53. Ågren, G. Temperature dependence of old soil organic matter. Ambio 29, 55 (2000).

54. Luo, Y., Wan, S. \& Hui, D. Acclimatization of soil respiration to warming in tall grass prairie. Nature 413, 622-625 (2001).

55. Melillo, J. M. et al. Soil warming and carbon-cycle feedbacks to the climate system. Science 298, 2173-2175 (2002).

56. Holland, E. A. et al. Uncertainties in the temperature sensitivity of decomposition in troical and subtrocipal ecosystems: Implications for models. Glob. Biogeochem. Cycles 14, 1137-1151 (2000).

57. Fang, C. et al. Is resistant soil organic matter more sensitive to temperature then the labile organic matter? Biogeosci. Discuss. 2, 725-735 (2005).

58. Rustad, L. E. et al. A meta-analysis of the response of soil respiration, net nitrogen mineralization, and aboveground plant growth to experimental ecosystem warming. Oecologia 126, 543-562 (2001)

59. Eliasson, P. E. et al. The response of heterotrophic $\mathrm{CO}_{2}$-flux to soil warming. Glob. Change Biol. 11, 167-181 (2005)

60. Kirschbaum, M. U. F. Soil respiration under prolonged soil warming: are rate reductions caused by acclimation or substrate loss? Glob. Change Biol. 10, 1870-1877 (2004).

61. Knorr, W. et al. On the available evidence for the temperature dependence of soil organic carbon. Biogeosci. Discuss. 2, 749-755 (2005).

62. Reichstein, M. et al. Does the temperature sensitivity of decomposition vary with soil organic matter quality? Biogeosci. Discuss. 2, 737-747 (2005).

63. Wetherald, R. T. \& Manabe, S. Detectablity of summer dryness caused by greenhouse warming. Clim. Change 43, 495-511 (1999).

64. Freeman, C., Ostle, N. \& Kang, H. An enzymatic 'latch' on a global carbon store. Nature 409, 149 (2001).

65. Maltby, E. \& Immirzi, P. Carbon dynamics in peatlands and other wetland soils regional and global perspectives. Chemosphere 27, 999-1023 (1993)

66. Whalen, S. C., Reeburgh, W. C. \& Reeburge, W. S. Consumption of atmospheric methane by tundra soils. Nature 346, 160-162 (1990).

67. Ramaswamy, V. et al. in Climate Change 2001: The Scientific Basis (eds Houghton, J. T. et al.) 349-416 (Cambridge Univ. Press, Cambridge, UK, 2001).

68. Shaver, G. S. et al. Global change and the carbon balance of arctic ecosystems. Bioscience 42, 433-441 (1992)

69. Grogan, P. \& Jonasson, S. Temperature and substrate controls on intra-annua variation in ecosystem respiration in two subarctic vegetation types. Glob. Change Biol. 11, 465-475 (2005)

70. Turetsky, M. R., Wieder, R. K., Halsey, L. A. \& Vitt, D. H. Current disturbance and the diminishing peatland carbon sink. Geophys. Res. Lett. 29, 10.1029/ 2001GL014000 (2002). 
71. Turetsky, M. R., Amiro, B. D., Bosch, E. \& Bhatti, J. S. Historical burn area in western Canadian peatlands and its relationship to fire weather indices. Glob. Biogeochem. Cycles 18, 4014, doi:10.1029/2004GB002222 (2004).

72. Page, S. E. et al. The amount of carbon released during peat and forest fires in Indonesia during 1997. Nature 420, 61-65 (2002).

73. Chapin, F. S. III et al. Arctic and boreal ecosystems of western North America as components of the climate system. Glob. Change Biol. 6 (suppl. 1), 211-233 (2000)

74. Osterkamp, T. E. \& Romanovsky, V. E. Evidence for warming and thawing of discontinuous permafrost in Alaska. Permafrost Periglacial Process. 10, 17-37 (1999).

75. Serreze, M. C. et al. Observational evidence of recent change in the northern high-latitude environment. Clim. Change 46, 159-207 (2000).

76. Goulden, M. L. et al. Sensitivity of boreal forest carbon balance to soil thaw. Science 279, 214-217 (1998).

77. Anisimov, O. A., Nelson, F. E. \& Pavlov, A. V. Predictive scenarios of permafrost development under conditions of global climate change in the $X X$ century. Earth Cryology 3, 15-25 (1999).

78. Zimov, S. A. et al. North Siberian lakes: a methane source fueled by Pleistocene carbon. Science 277, 800-802 (1997).

79. Smith, L. C., Sheng, Y., MacDonald, G. M. \& Hinzman, L. D. Disappearing arctic lakes. Science 308, 1429 (2005).

80. Ogle, S. M., Breidt, F. J., Eve, M. D. \& Paustian, K. Uncertainty in estimating land use and management impacts on soil organic carbon storage for US agricultural lands between 1982-1997. Glob. Change Biol. 9, 1521-1542 (2003)

81. Post, W. M. et al. Enhancement of carbon sequestration in US soils. Bioscience 54, 895-908 (2004).

82. Telles, E. C. C. et al. Influence of soil texture on carbon dynamics and storage potential in tropical forest soils of Amazonia. Glob. Biogeochem. Cycles 17, 1040, 9-1-12, doi:10.1029/2002GB001953 (2003).

83. Lichter, J. et al. Soil carbon sequestration and turnover in a pine forest after six years of atmospheric $\mathrm{CO}_{2}$ enrichment. Ecology 86, 1835-1847 (2005).

84. van 't Hoff, J. H. Lectures on Theoretical and Physical Chemistry. Part 1. Chemical Dynamics (Edward Arnold, London, 1898).

85. Arrhenius, S. Uber die Reaktionsgeschwindigkeit bei der Inversion von Rohrzucker durch Sauren. Z. Phys. Chem. 4, 226-248 (1889).

86. Tjoelker, M. G., Oleksyn, J. \& Reich, P. B. Modelling respiration of vegetation: evidence for a temperature-dependent $\mathrm{Q}_{10}$. Glob. Change Biol. 7, 223-230 (2001).

87. Imriskova, I. et al. Biochemical characterization of the glucose kinase from Streptomyces coelicolor compared to Streptomyces peucetius var. caesius. Res. Microbiol. 156, 361-366 (2005).

88. Michaelis, L. \& Menten, M. L. Die kinetik der invertin wirkung. Biochem. Z. 49, 334-336 (1913)

89. Atkin, O. K. \& Tjoelker, M. G. Thermal acclimation and the dynamic response of plant respiration to temperature. Trends Plant Sci. 8, 343-351 (2003).
90. Berry, J. A. \& Raison, J. K. in Physiological Plant Ecology I. Responses to the Physical Environment (eds Lange, O. L. et al.) 277-388 (Springer, Berlin, 1981).

91. Davidson, E. A., Janssens, I. A. \& Luo, Y. On the variability of respiration in terrestrial ecosystems: moving beyond $\mathrm{Q}_{10}$. Glob. Change Biol. (in the press); published online 8 December 2005 (doi:10.1111/j.1365-2486.2005.01065.x).

92. Linkins, A. E., Melillo, J. M. \& Sinsabaugh, R. L. in Current Perspectives in Microbial Ecology (eds Klug, M. J. \& Reddy, C. A.) 572-579 (American Society for Microbiology, Washington DC, 1984).

93. Koch, K. E. Carbohydrate-modulated gene expression in plants. Annu. Rev. Plant Physiol. Plant Mol. Biol. 47, 509-540 (1996).

94. Sheen, J. Feedback control of gene expression. Photosynth. Res. 39, 427-438 (1994)

95. Atkin, O. K., Bruhn, D., Hurry, V. M. \& Tjoelker, M. G. The hot and the cold: unravelling the variable response of plant respiration to temperature. Funct. Plant Biol. 32, 87-105 (2005)

96. Dalias, P., Anderson, J. M., Bottner, P. \& Coûteaux, M. M. Temperature response of carbon mineralization in conifer forest soils from different regional climates incubated under standard laboratory conditions. Glob. Change Biol. 7, 181-192 (2001)

97. Dalias, P., Anderson, J. M., Bottner, P. \& Coûteaux, M. M. Long-term effects of temperature on carbon mineralisation processes. Soil Biol. Biochem. 33, 1049-1057 (2001).

98. Hyvönen, R., Ågren, G. I. \& Dalias, P. Analysing temperature response of decomposition of organic matter. Glob. Change Biol. 11, 770-778 (2005).

99. Zak, D. R., Holmes, W. E., MacDonald, N. W. \& Pregitzer, K. S. Soil temperature, matric potential, and the kinetics of microbial respiration and nitrogen mineralization. Soil Sci. Soc. Am. J. 63, 575-584 (1999).

100. Soil Organic Carbon Map (US Department of Agriculture, Natural Resources Conservation Service, Soil Survey Division, World Soil Resources, Washington DC); 〈http://soils.usda.gov/use/worldsoils/mapindex/soc.html〉 (1997; revised 2000).

Acknowledgements We thank G. Ågren, R. Houghton, C. Potter, D. Sampson J. Schimel, P. Smith and D. Thompson for comments on earlier drafts of this paper. We thank M. Ernst for assistance with graphics. E.A.D. acknowledges support from the Northeast Regional Center of the National Institute for Global Environmental Change of the Department of Energy and by the National Science Foundation. I.A.J. acknowledges the European Commission for support via CarboEurope-IP. Financial support does not constitute an endorsement by DOE or NSF of the views expressed in this article.

Author Information Reprints and permissions information is available at npg.nature.com/reprintsandpermissions. The authors declare no competing financial interests. Correspondence should be addressed to E.A.D. (edavidson@whrc.org). 